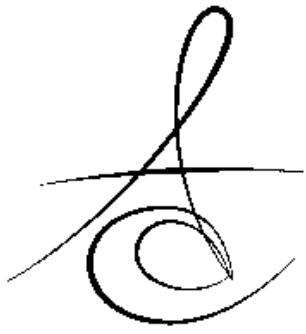

\title{
ÜÇ FARKLI SELF-ETCH ADEZIVİN DEMİR SÜLFAT İLE KONTAMİNE SÜT Dİşİ DENTÍNİNE BAĞLANMA DAYANIMLARININ KARŞILAŞTIRILMASI ${ }^{*}$
}

\section{COMPARING OF MICROTENSILE BOND STRENGTH OF THREE DIFFERENT SELF-ETCH ADHESIVE SYSTEMS TO PRIMARY TOOTH DENTINE CONTAMINATED WITH FERRIC SULPHATE}

\author{
Yrd. Doç. Dr. Gülsüm DURUK* \\ Dr. Veli Alper GÖRGEN ${ }^{* *}$
}

Araş. Gör. Dt. Neslihan KAYA***

Makale Kodu/Article code: 2900

Makale Gönderilme tarihi: 23.06.2016

Kabul Tarihi: 22.11.2016

\section{ÖZET}

Amaç: Bu çalışmanın amacı demir sülfat ile kontamine süt dişi dentinine 3 farklı self-etch adeziv sistemlerin asitli ve asitsiz uygulamalarını takiben yerleştirilen kompomerin mikrogerilim bağlanma dayanımlarını değerlendirmektir.

Materyal-Metod: 45 adet çürüksüz insan süt II. azı dişinin kuronları, okluzalden dentin yüzeyi açığa çıkacak şekilde yatay yönde uzaklaştırılmış ve eşit sayıda rastgele 3 gruba ayrılmıştır. Grup I: kontrol, Grup II: demir sülfatla kontamine, Grup III: demir sülfatla kontamine asit uygulanan grup. Her bir grup kendi içinde 3 farklı adeziv ajan (Clearfil SE-Bond, 3M-ESPE Single Bond Universal, Tokuyama Bond Force) için 3 alt gruba ayrımıştır. Grup II ve III'teki dişler insan kanıyla kontamine edildikten sonra 30 sn demir sülfat uygulanmış ve 30 sn süreyle serum fizyolojik ile yıkanmıştır. Grup III'e \%34,5' lik fosforik asit 15 sn uygulanmıştır. Tüm gruplara adeziv uygulaması ve kompomer restorasyonu sonrası, dişler 1x1 mm kalınlığında kesilerek her dişten 3'er adet test çubukları elde edilmiştir. Çubuklara mikrogerilim testi uygulanmıştır. Oluşan kırık tipleri (adeziv, koheziv, karışık) steromikroskopta belirlenmiştir. Verilerin değerlendirilmesinde tek yönlü varyans analizi ve Posthoc çoklu karşılaştırma testleri kullanılmıştır.

Bulgular: En düşük mikrogerilim değeri Grup II'de iken $(p<0,05)$, en başarılı adeziv Grup I ve II de Clearfil SEBond bulunmuştur.

Sonuç: Demir sülfat, süt dişi dentininde self-etch adezivlerin bağlanma performansları üzerine negatif etkiye sahip olup, asit uygulaması bu etkiyi azaltmaktadır. Anahtar Kelimeler: Bağlanma dayanımı, demir sülfat, kontaminasyon.

\section{ABSTRACT}

Aim: The aim of this study was to evaluate the microtensile bond strengths of compomer placed to primary dentin contaminated with ferric sulphate following the application of three different acidic and acid-free self-etch adhesive systems.

Materials and method: 45 non-carious second primary molars human teeth were cut horizontally so as to be released the occlusal dentin surface. Teeth were randomly divided into 3 groups with equal numbers. Group I: control, Group II: contaminated with ferric sulphate, Group III: exposed to acid contaminated with ferric sulphate. Each group was divided into 3 subgroups for 3 different adhesive agents (Clearfil SE-Bond, 3MESPE Single Bond Universal, Tokuyama Bond ForceII). After the teeth were contaminated with human blood in group II and III, ferric sulphate was applied to teeth for 30 seconds and they were rinsed with physiological serum for 30 seconds. $34.5 \%$ phosphoric acid was applied to teeth in group 3 for 15 seconds. After the application of adhesive and compomer restoration to all groups, 3 test sticks from each tooth were obtained by cutting the teeth to $1 \times 1 \mathrm{~mm}$. Microtensile test was applied to the strips and fracture types (adhesive, cohesive, mixed) obtained were determined at stereomicroscope. The data were analyzed by one-way ANOVA and Post-Hoc test.

Results: The lowest value of microtensile has been found in Group II $(p<0.05)$. The most successful adhesive was Clearfil SE-Bond in Group I and Group II.

Conclusion: Ferric sulphate has a negative effect on bonding performance of self-etch adhesives at primary dentine and acidic applications reduce this effect.

Key Words: Bond strength, ferric sulphate, contamination

\footnotetext{
*İnönü Üniversitesi Diş Hekimliği Fakültesi Pedodonti Anabilim Dalı

${ }^{* *}$ Serbest Hekim, Pedodonti Uzmanı

${ }^{* * *}$ Ankara Üniversitesi, Diş Hekimliği Fakültesi Pedodonti Anabilim Dalı

\# Bu çalışma 22. Türk Pedodonti Derneği Kongresinde sözlü bildiri olarak sunulmuştur.

2-5 Kasım 2015, Kıbrıs
} 


\section{GİRİŞ}

Pulpatomi uygulamalarında kullanılan en yaygın materyal formokrezol olmuştur. ${ }^{1}$ Ancak formokrezolün bazı olumsuz özelliklerinden dolayı, ${ }^{2}$ non-aldehit esaslı demir sülfat (DS), süt dişi pulpatomi tedavilerinde formokrezole alternatif olmuş ve başarılı sonuçlar elde edilmiştir. ${ }^{3}$ Pulpatomi uygulanmış dişlerde üst restorasyon klinik başarıyı direk etkilemektedir. Üst restorasyon olarak paslanmaz çelik kuronlar (PÇK), amalgamlar ve daha estetik olan kompozit veya kompomer rezin restoratifler kullanılmaktadır. Yapılan çalışmalar gluteraldehit ve formokrezol materyallerine benzer şekilde DS'nin de rezin esaslı restoratif materyallerin süt dişi dentin yüzeylerine bağlanma gücünü olumsuz etkilediğini göstermiştir. ${ }^{4,5}$

DS ile kontamine olmuş süt dişi dentin yüzeylerine total etch tekniği ile "single component" bağlayıcı ajan uygulaması sonrası yerleştirilen kompozit rezinin bağlanma gücünde azalma oluştuğu bildirilmiştir. ${ }^{4}$ Bir başka çalışmada, DS ile kontamine süt dişi dentin yüzeylerine self-etch dentin bağlayıcı ajan uygulaması sonrası yapılan kompozit rezin restorasyonun yeterli bağlanma gücü oluşturmadığı kaydedilmiştir. $^{5}$

Adeziv sistemler; self-etch, etch \& rinse (total etch) ve cam iyonomer esaslı olmak üzere 3'e ayrılarak değerlendirilebilir. Self-etch adezivler klinik kullanımlarının kolay olması ve teknik hassasiyetlerinin düşük olmasından ötürü daha fazla tercih edilmektedir. $^{6}$ Ancak, self-etch adezivler smear tabakasının bir bölümünü çözebilirler, dentin yüzeyinde etch\&rinse sistemler kadar derin demineralizasyonlar yapamazlar.7 Diş sert dokularını fosforik asit kadar dağlayamadıklarından düşük bağlanma dayanımı gösterirler. ${ }^{8,9}$

Bu çalışmada, DS ile kontaminasyon sonrası süt dişi dentinine \%34,5'lik fosforik asitli (etch\&rinse) ve asitsiz (self-etch) olarak üç farklı self-etch adezivin ayrı ayrı uygulanması sonrası kompomer rezinin bağlanma gücü üzerine etkilerinin değerlendirilmesi amaçlanmıştır.

\section{GEREÇ VE YÖNTEM}

Yapılan power analizine göre, çalışmamız \%95 güven aralığında olup, \%80 güç ile her bir grupta örnek sayısının en az 12 olması gerektiği hesaplanmıştır. ${ }^{10}$ Çalışma için gerekli etik kurul onayı, Malatya Klinik Araştırmalar Etik Kurulu'ndan alınmıştır (16/141). Çalışmada fizyolojik kök rezorbsiyonu nedeniyle çekilmiş çürüksüz 45 adet insan süt II. azı dişi kullanıldı. Dişlerdeki mevcut debris ve yumuşak doku artıkları periodontal küret ve pomza\&lastik yardımıyla temizlendi. Dişler deney için kullanılıncaya kadar distile su içerisinde bekletildi. Dişlerin tüberkülleri okluzal bölgede düzgün dentin yüzeyi elde edebilmek için dişlerin uzun aksına dik olarak elmas separe aracılığıyla kaldırıldı. Açı̆̆a çıkan dentin yüzeyi ve oluşan smear tabakasını homojenize etmek için 180 gritlik su zımparası yardımıyla 10 sn boyunca zımparalama işlemi yapıldı. Hazırlanan tüm diş numuneleri rastgele her bir grupta 15 diş olacak şekilde 3 gruba ayrıldı.

Grup I: Kontrol

Grup II: Kan ve DS ile kontamine dişler (self-etch)

Grup III: Kan ve DS ile kontamine asit uygulanan dişler (etch \& rinse)

Daha sonra her bir grup 3 alt gruba ayrıldı $(n=5)$.

Grup II ve III'teki dişler taze insan kanıyla kontamine edildikten sonra 30 sn süreyle serum fizyolojik ile yıkandı, 30 sn demir sülfat (Viscostat MetalDentalInfuser, Ultradent, Products, South Jardon, Utah, USA) uygulandı ve tekrar 30 sn süreyle serum fizyolojik ile yıkandı. Grup III'e \%34, $5^{\prime}$ lik fosforik asit 15 sn kadar uygulandıktan sonra 15 sn boyunca suyla yıkandı. Dentin yüzeyleri üzerindeki fazla su mikrosüngerlerle uzaklaştırılarak dentin yüzeyleri hazırlandı.

Her bir grup kendi içinde 3 farklı self-etch adeziv ajan için 3 alt gruba ayrıldı $(n=5)$. Self-etch adeziv olarak Clearfil SE-Bond (CSE), 3M-ESPE Single Bond Universal (3M Uni), Tokuyama Bond Force seçilmiştir. Kullanılan self-etch adezivlerin içerikleri ve uygulama prosedürleri Tablo 1'de gösterilmiştir.

Bonding ajan uygulanan örneklere $2 \mathrm{~mm}$ yüksekliğe sahip teflon disk kalıp yardımı ile $2 \mathrm{~mm}$ kaIınlıkta kompomer (Dyract, Dentsply DeTrey, Konstanz, Germany) üretici firmanın önerileri doğrultusunda tek kat uygulanıp 40 sn polimerize edildi.

\section{ikrogerilim Bağlanma Dayanımı Testi}

Örnekler distile su içerisinde mikrogerilim bağlanma dayanımı ( $\mu \mathrm{GBD}$ ) testi öncesi $37^{\circ} \mathrm{C}$ etüvde 24 saat bekletildi ve sonrasında dişlerin kökleri minesement hududuna kadar akrilik bloklara gömüldü.

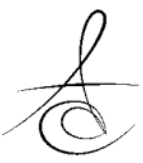


Tablo 1. Kullanılan materyaller ve uygulama prosedürleri

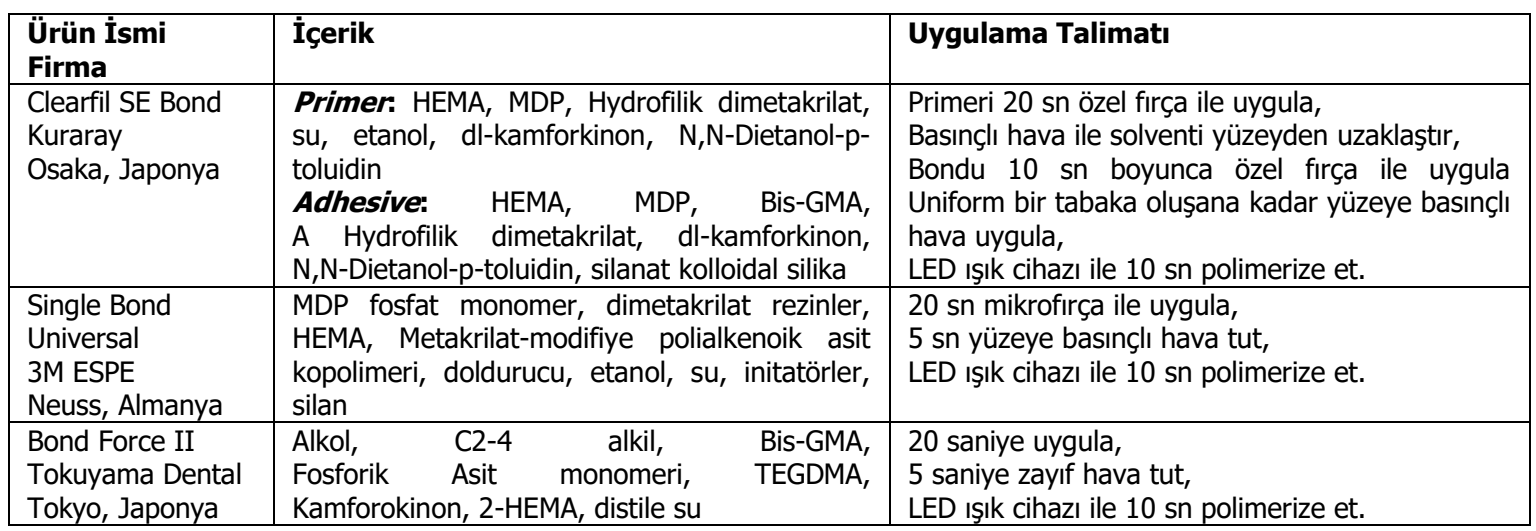

Mikro kesitler elde etmek için, bloklar kesme cihazina (Isomet 1000, Buehler Ltd., Lake Bluff, IL, USA) yerleştirildi. Kompomer ve süt dişinden oluşan örneklerden dişin uzun aksına paralel olacak şekilde yaklaşık $1 \mathrm{~mm}^{2}$ lik kare kesitli test çubukları elde edildi. Her bir kompomer-diş numunesinden elde edilen test çubuklarının 3'er tanesi alındı. Böylece her bir grup için $15^{\prime} e r$ adet test çubuğu elde edilmiş oldu $(n=15)$. Bu işlem sırasında başarısızık sergileyen örnekler çalışma dışı bırakıldı. Numuneler sıcaklığı $5-55^{\circ} \mathrm{C}$ arasında değişen su banyolarının herbirinde 20 sn bekletilmek üzere $500 \mathrm{kez}$ ısısal döngüye tabi tutuldu.

$\mu \mathrm{GBD}$ testi için, test çubukları mikro gerilim test cihazına (Mikrotensile tester, Bisco, Schamburg, ABD) bir siyanoakrilat yapışıııı yardımıyla iki ucundan yapışııııldı. Test cihazının yükleme hızı $1 \mathrm{~mm} / \mathrm{dk}$ ve yükleme kuvveti $100 \mathrm{~N}$ olarak belirlendi ve test çubukları kırılma testine tabi tutuldu. Dijital mikrometre ile test çubuklarının kenar uzunlukları ölçülüp, bağlanma yüzey alanları hesaplandı. Newton cinsinden elde edilen değerler yüzey alanına bölünüp $\mathrm{MPa} a$ çevrildi.

\section{Kırılma Analizleri}

$\mu G B D$ testine tabi tutulan numunelerin stereomikroskop (Olympus SZ4045 TRPT, Osaka, Japonya) altında X20 büyütmede başarısızlık şekilleri incelendi. Başarısızık tipleri "adeziv" (dentin- kompo- mer ara yüzeyinden kopma), "koheziv" (dentin veya kompomerden kopma) ve "karışık"(adeziv+ koheziv) şeklinde belirlendi.

\section{İstatistiksel Değerlendirme}

Elde edilen veriler SPSS 21.0 (IBM, Chicago, USA) istatistik programında, \%5 önem seviyesinde analiz edildi.
Örneklerin normal dağılıma uyup uymadığını görmek için Shapiro- Wilk testi yapıldı. Elde edilen $\mu G B D$ verileri tek yönlü ANOVA ve Post- hoc çoklu karşılaşııma testleri ile, başarısızlık tipleri ise tek yönlü Kruskal Wallis testi ile değerlendirildi.

\section{BULGULAR}

$\mathrm{Bu}$ çalışmada kullanılan bonding sistemlerden elde edilen $\mu \mathrm{GBD}$ değeri ortalamaları Tablo 2'de özetlenmiş̧ir. Gruplar arası farklılık istatistiksel olarak anlamlı bulunmuştur $(p<0,05)$. En düşük $\mu G B D$ ortalama değeri Grup II'de iken, en yüksek $\mu \mathrm{GBD}$ ortalama değeri Grup III'te bulunmuştur. İstatistiksel açıdan farkllığa sebep olan ortalama değerler Tablo 2'de farklı harfler ile gösterilmiştir.

Tablo 2. Örneklerin $\mu$ GBD'nın MPa cinsinden Ortalama \pm Standart sapma değerleri

\begin{tabular}{|l|c|l|l|}
\hline \multicolumn{4}{|c|}{ Ortalama \pm Standart sapma (MPa) } \\
\hline & CSE & 3 M Uni & Tokuyama \\
\hline Grup I & $23,18 \pm 2,30^{\mathrm{a}}$ & $20,07 \pm 4,73^{\mathrm{b}}$ & $19,98 \pm 3,02^{\mathrm{b}}$ \\
\hline Grup II & $17,70 \pm 2,88$ & $14,38 \pm 2,77^{\mathrm{c}}$ & $14,31 \pm 2,19^{\mathrm{c}}$ \\
\hline Grup III & $24,98 \pm 1,77^{\mathrm{a}}$ & $23,93 \pm 1,14^{\mathrm{a}}$ & $23,81 \pm 2,33^{\mathrm{a}}$ \\
\hline
\end{tabular}

Grup I ve Grup II' de en yüksek bağlanma daya- nımını CSE sergilemiştir ( $p>0,05)$. Grup III'te adezivler arasında istatistiksel fark ile karşılaşılmamıştır.

Başarısızlık tiplerinin dağılımı Tablo $3^{\prime}$ de gösterilmiştir. Tüm gruplarda başarısızlık tipi sıklıkla "adeziv" olarak belirlenmiştir. Gruplar arası farklılık istatistiksel olarak anlam ifade etmemektedir. $(p>0,05)$. 


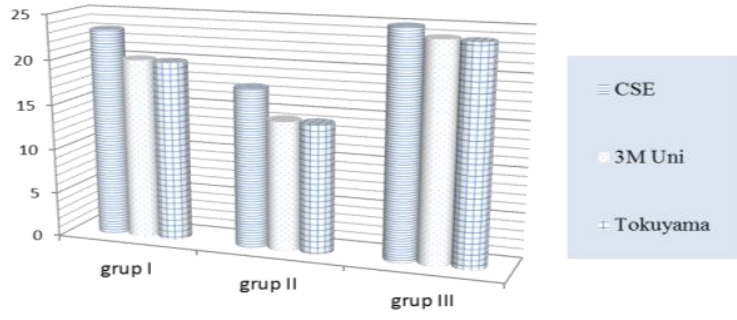

Şekil 1. $\mu G B D$ ortalama değerlerinin grafiksel gösterimi (MPa).

Tablo 3. $\mu \mathrm{GBD}$ testi sonrası örneklerdeki kırılma modelleri.

\begin{tabular}{|l|l|l|l|l|}
\hline \multicolumn{5}{|c|}{ BaşarıSızlık tipleri } \\
\hline & & Adheziv & Koheziv & Karışık \\
\hline \multirow{3}{*}{ Gurup I } & CSE & 13 & 1 & 1 \\
\cline { 2 - 5 } & 3 M Uni & 14 & 1 & - \\
\cline { 2 - 5 } & Tokuyama & 14 & 1 & - \\
\hline \multirow{3}{*}{ Gurup II } & CSE & 13 & 2 & - \\
\cline { 2 - 5 } & 3 M Uni & 15 & - & - \\
\cline { 2 - 5 } & Tokuyama & 15 & - & - \\
\hline Gurup III & CSE & 11 & 2 & 2 \\
\cline { 2 - 5 } & $3 M$ Uni & 13 & 2 & - \\
\cline { 2 - 5 } & Tokuyama & 12 & 2 & 1 \\
\hline
\end{tabular}

\section{TARTIŞMA}

Diş preparasyonlarında kavite açımı sırasında dişeti travmaları ya da pulpatomi uygulamalarında pulpal kanamanın hemostazı için kimyasal ajanların kullanılması sonucu dentin yüzeyi kan ve kanama durdurucu ajanlarla kontamine olabilir. Klinik uygulamlarda kanama durdurucu ajan olarak çoğunlukla bünyesinde metal solüsyonları barındıran ajanlar kullanılır. ${ }^{11}$ Kanama durdurucu ajan olarak kullanılan DS materyali aynı zamanda süt dişi pulpatomi uygulamalarında da kullanılmaktadır. Çalışmamızda DS materyali tercih edilmiştir. Klinik pratikte süt dişi amputasyon tedavilerinde pulpal kanama nemli steril pamuk tamponlarla kontrol altına alınmakta, amputasyon kavitesi ve kanla kontamine çevre dentin serum fizyolojik ile yıkanmakta ve pulpal hemostazı sağlamak amacıyla hemostatik ajan uygulanmaktadır. Bu çalışmada, çalışma grubunda invivo koşulları simüle etmek amacıyla öncelikli olarak dentin yüzeyler taze insan kanı ile kontamine edilmiş, kan serum fizyolojik ile dentinden uzaklaştırıldıktan sonra DS ile kontaminasyona geçilmiştir.

DS materyali (Viscostat) oldukça visköz ve asidiktir $(\mathrm{pH} \approx 1)$. Materyal asiditesinden dolayı uygulama sonrası, yüzeyde bulunan smear tabakayı ya çözer ya da modifiye eder ve sonunda yüzeye kendisi oturur. $^{12}$ Demir solüsyonuna maruz kalan mine yüzeyinde $10 \mu \mathrm{m}$ derinliğe kadar demirin absorbsiyonu gerçekleşmekte ve ferrik hidroksiapatit bileşiği oluşmakta, fakat hidroksiapatit kristallerinin çözünürlüğü etkilenmemektedir. ${ }^{13,14}$

DS ile dentin yüzeylerinin kontaminasyonu sonrası dentindeki kollajen fibriller ve plazma proteinleri koagülasyona uğrar. ${ }^{12}$ Koagülasyona uğramış protein ve DS artıkları dağlanmış mine ve dentin yüzeylerinde bağlayıcı ajanın infiltrasyonunu azaltır. ${ }^{15}$

Bu çalışmada self-etch bonding sistemlerin kontamine dentine bağlanma dayanımları kontrol grubundan istatistiksel olarak anlamlı bir düşüş sergilemiştir. Düşük bağlanma dayanımının sebebi DS ile kontamine olan kollajen fibrillerin ve dentin plazma proteinlerin koagülasyonu olabilir. ${ }^{12}$

Self-etch adeziv sistemlerin dentine bağlanma mekanizmaları, smear tabakanın değiştirilmesi ve açığa çıkan kollajen fibrillere adezivin infiltrasyonu ile oluşan hibrit tabaka aracılığı ile gerçekleşir. ${ }^{16}$ Fakat kullandığımız self-etch sistemlerin primerlarının zayıf asitliğe sahip olması ve ilave yıkama işlemi içermemeleri sebebiyle istenilen kalınlıkta hibrit tabaka oluşturacak kadar koagüle ajanları uzaklaştıramadıklarından bağlanma dayanımları azalmış olabilir.

Sonuç olarak self-etch primerlerin dentini daha az dağlaması bu çalışmada olduğu gibi bağlanma dayanımını azaltabilir. Prabhakar ve Bedi ${ }^{1}$ dentin yüzeylerinin glutaraldehit ve DS ile kontaminasyonun selfetch adezivlerin bağlanma dayanımlarını düşürdüğünü bildirmişlerdir. Kuphasuk ve arkadaşları, ${ }^{11}$ self-etch primerin uygulama süresinin uzatılmasının etching etkisini artırarak kontamine dentine bağlantının artacağını bildirmişlerdir.

Dentinin kanama durdurucu ajanlarla kontamine olmasının etch \& rinse adeziv sistemlerin bağlanma dayanımı üzerine ciddi bir etkinliğinin olmadığı, $\mathrm{pH}$ 'sı 0,5 olan fosforik asitin belirgin etching etkisiyle DS solüsyonlarından etkilenen dentin ve tüm koagülasyon unsurlarını ortamdan uzaklaştırılabileceği belirtilmiştir. ${ }^{17,18}$ Bu çalışmada self-etch adezivlerin etch \& rinse tekniğiyle uygulanması sonucu DS ile kontamine grupta bağlanma değerlerinin en yüksek olduğu tespit edilmiştir. Asit uygulaması sonrası kontaminasyon tamamen elimine edildiği gibi bağlanma dayanımı da, self etch tekniğinin önüne geçmiştir.

Tüm adeziv sistemler aynı koşullarda test edilmiş olmalarına rağmen adezivler arasında bağlantı kuvveti açısından farklar tespit edilmiştir. Bunun 
sebebi olarak ürünlerin içerikleri ve yapıları gösterilebilir. CSE ve 3M Uni yapılarında 10-metakriloloksidesil dihidrojen fosfat (MDP) monomer içerdiklerinden dolayı dentine kimyasal olarak bağlanabilirler. ${ }^{8,19}$ Yoshida ve arkadaşları ${ }^{20}$ MDP monomer ve hidroksiapatit arasında meydana gelecek etkili bir kimyasal bağlanmanın, bağlantı ara yüzünün mekanik direncini arttıran ve ara yüzün en dayanıklı hale kavuşmasını sağlayan stabil bir nanotabaka oluşturduğunu belirtmişlerdir. Yüksek bond dayanıklıığı MDPCa tuzlarının bağlantı ara yüzündeki nano tabaka boyunca çökelmesine dayandırılmıştır. ${ }^{20} \mathrm{Bu}$ çalışmada kullanılan her iki materyal de MDP içermesine rağmen bağlanma dayanımında farklılıklar mevcuttur. Bu fark Barutçugil ve arkadaşlarının ${ }^{21}$ çalışmasına benzer olarak 3M Uni'nin içeriğinde polialkenoik asit kopolimeri bulundurmasından kaynaklanıyor olabilir. Yoshida ve arkadaşları, ${ }^{20}$ bu kopolimerin hidroksiapatitteki kalsiyum ile bağlanmak için MDP monomeri ile yarıştığını ve MDP'nin bağlanabilirliğini azalttığını belirtmişlerdir. Bu kopolimer hidroksiapatit içerisindeki kalsiyum ile kimyasal bağ kurar. ${ }^{22}$ Polialkenoik asit kopolimerlerinin içeriğindeki karboksil gruplarının \%50'den fazlası hidroksiapatitlerle bağ kurar. Karboksil grupları, fosfat iyonlarıyla yer değiştirip, kalsiyum ile iyonik bağ oluştururlar. ${ }^{23}$ Bununla birlikte polialkenoik asit kopolimeri, yüksek moleküler ağırlığı sebebiyle polimerizasyon sırasında monomerlerin yakınlaşmasını engelleyerek de MDP monomerin bağlanmasını azaltabilir. Bunu destekleyecek şekilde 3M Uni adezivinin konversiyon oranının CSE'den az olduğu daha önceki bir çalışmada ortaya konulmuştur. ${ }^{21,24}$

3M Uni'nin daha düşük bağlanma dayanımı verileri göstermesinin sebebi yapısında MDP monomer ile birlikte polialkenoik asit kopolimeri ve HEMA monomerleri bulundurmasıyla ilişkili olabilir. ${ }^{20,21}$

Tüm self-etch adezivler içerisinde en düşük bağlanma dayanımını istatistiksel anlam ifade etmese de Bond Force II adeziv göstermiştir. Bond Force II tek aşamalı bir self-etch adeziv sistemdir ve içeriğinde bağlanma dayanımını arttırdığı söylenen MDP monomeri bulunmamaktadır.

Bağlanma dayanımını, materyalin $\mathrm{pH}$ değeri, çözücünün tipi ve doldurucu oranı belirler. ${ }^{25}$ Self-etch sistemlerin içeriğindeki primerin asiditesi; güçlü $(\mathrm{pH}<1)$, orta $(\mathrm{pH} 1-2)$ ve zayıf $(\mathrm{pH}>2)$ olarak gruplandırılır. ${ }^{26} \mathrm{Bu}$ çalışmada, kullanılan materyallerin $\mathrm{pH}$ değeri zayıf asit grubuna girmektedir. CSE ve 3M Uni çözücü olarak su ve etanol içerirken, Bond Force
II'nin çözücüsü alkoldür. Alkol içerikli dentin bağlayıcı ajanlar ortamdaki sudan fazla etkilenmemekle birlikte diğer organik çözücüler kadar kolay buharlaşmamaktadır. ${ }^{27}$ Bond Force II'nin buharlaşması daha geç olan alkol ve su ihtiva etmesi ve ayrıca MDP monomeri içermemesi bağlanma dayanımının düşük değerler sergilemesinin sebebi olarak açıklanabilir. ${ }^{28}$ Sonuç olarak; bu çalışmada kullanılan her 3 dentin bağlayıcı ajan da zayıf asit grubundan olup, asidik etkinliklerinin içerdikleri asidik monomerlerden kaynaklı olduğu düşünülmektedir. ${ }^{28}$ Çalışmamızda, bu self-etch adezivleri etch \& rinse tekniğiyle uyguladığımızda bağlanma dayanımları benzer değerler sergilemiştir.

\section{SONUÇ VE ÖNERİ}

DS ajan kullanıldığı durumlarda daha yüksek bağlanma dayanımı elde etmek için süt dişi dentininde self-etch sistemler yerine etch \& rinse sistemleri tercih etmek daha doğru olabilir. Bu çalışmanın sınırları içerisinde kullanılan bağlayıcı ajanlar dışındaki farklı materyaller farklı sonuçlar sergileyebilir. Bu sebeple farklı adeziv sitemlerin farklı uygulama teknikleriyle uygulandığı yeni çalışmalara ihtiyaç vardır.

\section{KAYNAKLAR}

1. Prabhakar AR, Bedi S. Effect of glutaraldehyde and ferric sulfate on shear bond strength of adhesives to primary dentin. J Indian Soc Pedod Prev Dent 2008;26:109-13.

2. Zarzar PA, Rosenblatt A, Takahashi CS, Takeuchi $\mathrm{PL}$, Costa Junior LA. Formocresol mutagenicity following primary tooth pulp therapy: an in vivo study. J Dent 2003;31:479-85.

3. Fuks $A B$, Holan $G$, Davis JM, Eidelman E. Ferric sulfate versus dilute formocresol in pulpotomized primary molars: long-term follow up. Pediatr Dent 1997;19:327-30.

4. Salama FS. Influence of zinc-oxide eugenol, formocresol, and ferric sulfate on bond strength of dentin adhesives to primary teeth. J Contemp Dent Pract. 2005;6:14-21.

5. Shalan H, Awad S, El-Fallal AA. Influence of pulpotomy medicaments on the ultrastructure and shear bond strength of a self-etch adhesive to primary tooth dentin. Quintessence Int 2012; 43: 517-23.

6. Inoue S, Koshiro K, Yoshida $\mathrm{Y}$, et al. Hydrolytic stability of self-etch adhesives bonded to dentin. J 
Dent Res 2005;84:1160-4.

7. Breschi L, Mazzoni A, Ruggeri A, Cadenaro M, Di Lenarda $R$, De Stefano Dorigo E. Dental adhesion review: aging and stability of the bonded interface. Dent Mater 2008;24:90-101.

8. Peumans M, De Munck J, Van Landuyt KL, Poitevin A, Lambrechts P, Van Meerbeek B. Eight-year clinical evaluation of a 2-step self-etch adhesive with and without selective enamel etching. Dent Mater 2010;26:1176-84.

9. Perdigao J, Carmo AR, Anauate-Netto C, et al. Clinical performance of a self-etching adhesive at 18 months. Am J Dent. 2005;18:135-40.

10. Keleş S, Derelioğlu S, Çelik P, Yılmaz Y. Demir Sülfat ile Kontamine Süt Dişi Dentininde Farklı Yüzey Uygulamalarının Kompomerin MikroGerilimine Etkisi. Atatürk Üniv Diş Hek Fak Derg 2013; 2:159-64.

11. Kuphasuk W, Harnirattisai C, Senawongse P, Tagami J. Bond strengths of two adhesive systems to dentin contaminated with a hemostatic agent. Oper Dent 2007;32:399-405.

12. Land MF, Rosenstiel SF, Sandrik JL. Disturbance of the dentinal smear layer by acidic hemostatic agents. J Prosthet Dent 1994;72:4-7.

13. Christoffersen MR, Thyregod HC, Christoffersen J. Effects of aluminum(III), chromium(III), and iron(III) on the rate of dissolution of calcium hydroxyapatite crystals in the absence and presence of the chelating agent desferrioxamine. Calcif Tissue Int 1987; 41:27-30.

14. Selvig KA, Halse A. The ultrastructural localization of iron in rat incisor enamel. Scand J Dent Res 1975;83:88-95.

15. Kumar P, Shenoy A, Joshi S. The effect of various surface contaminants on the microleakage of two different generation bonding agents: A stereomicroscopic study. J Conserv Dent 2012;15:265-9.

16. Moszner N, Salz U, Zimmermann J. Chemical aspects of self-etching enamel-dentin adhesives: a systematic review. Dent Mater. 2005;21:895-910.

17. Perdigao J, Gomes G, Lopes MM. Influence of conditioning time on enamel adhesion. Quintessence Int 2006; 37: 35-41.

18. Ünlü N, Çetin AR, Cebe MA, Karabekiroğlu S. Farklı Adeziv Sistemlerin Hemostatik Ajanlarla Kontamine Edilen Dentin Yüzeylerine Mikro Gerilim Bağlanma Dayanımlarının Karșılaștırıması. Hacettepe Diş Hek Fak Derg 2010;34: 5-13.
19. Waidyasekera K, Nikaido T, Weerasinghe DS, Ichinose S, Tagami J. Reinforcement of dentin in self-etch adhesive technology: a new concept. J Dent 2009;37:604-9.

20. Yoshida Y, Yoshihara K, Nagaoka N, et al. Selfassembled Nano-layering at the Adhesive interface. J Dent Res 2012;91:376-81.

21. Barutcigil Ç, Barutcigil K, Kürklü D, Harorlı OT. Güncel Dentin Bağlayıcı Ajanların ve Uygulama Yöntemlerinin Makaslama Bağlanma Dayanımlarının Karşılaştıııması. İnönü Üniv Sağlık Bil Derg 2013;2:27-32.

22. Mitra $S B$, Lee $C Y$, Bui HT, Tantbirojn D, Rusin RP. Long-term adhesion and mechanism of bonding of a paste-liquid resin-modified glass-ionomer. Dent Mater 2009;25:459-66.

23. Lin A, McIntyre NS, Davidson RD. Studies on the adhesion of glass-ionomer cements to dentin. J Dent Res 1992;71:1836-41.

24. Munoz MA, Luque I, Hass V, Reis $A$, Loguercio AD, Bombarda $\mathrm{NH}$. Immediate bonding properties of universal adhesives to dentine. J Dent 2013; 41: 404-11.

25. Atash $R$, Van den Abbeele A. Bond strengths of eight contemporary adhesives to enamel and to dentine: an in vitro study on bovine primary teeth. Int J Paediatr Dent 2005;15:264-73.

26. Finger WJ, Lee KS, Podszun W. Monomers with low oxygen inhibition as enamel/dentin adhesives. Dent Mater 1996;12:256-61.

27. Cheng JT, Itoh $K$, Kusunoki $M$, Hasegawa $T$, Wakumoto S, Hisamitsu $H$. Effect of dentine conditioners on the bonding efficacy of one-bottle adhesives. J Oral Rehabil 2005;32:28-33.

28. Şengün A, Yalçın $M$, Kocabasoglu A. Yedinci Jenerasyon Adeziv Sistemlerinin Dentine Makaslama Bağlanma Dayanımlarının Karşılastıııması. Atatürk Üniv Dis Hek Fak Derg 2009;19:156-60.

\section{Yazışma Adresi}

Yrd. Doç. Dr. Gülsüm DURUK

İnönü Üniversitesi Diş Hekimliği Fakültesi

Pedodonti Anabilim Dalı, Malatya

GSM: 0.536.7790404

e-mail: durukgulsum@yahoo.com 